\title{
Influence of Oxygen Vacancy in Mangan-based Catalyst on Phenol Removal Via Catalytic Ozonation
}

\author{
Liquan Xia ${ }^{1,2,3}$, Guifeng Chen ${ }^{2,3, ~}$, Wenbo $\mathrm{Li}^{2,3,}$, , Minglong Gao ${ }^{2,3}$, Jiaxin Zhao ${ }^{1,2,3}$ \\ ${ }^{1}$ China Coal Research Institute, Beijing, China \\ ${ }^{2}$ China Coal Research Institute Company Ltd., Beijing, China \\ ${ }^{3}$ State Key Laboratory of Coal Mining and Clean Utilization, Beijing, China
}

Email address:

liquanxia8059@126.com (Liquan Xia), chen@cct.org.cn (Guifeng Chen), wenbo-li@126.com (Wenbo Li)

*Corresponding author

\section{To cite this article:}

Liquan Xia, Guifeng Chen, Wenbo Li, Minglong Gao, Jiaxin Zhao. Influence of Oxygen Vacancy in Mangan-based Catalyst on Phenol Removal Via Catalytic Ozonation. Journal of Energy, Environmental \& Chemical Engineering. Vol. 5, No. 4, 2020, pp. 48-56.

doi: $10.11648 /$ j.jeece. 20200504.11

Received: October 16, 2020; Accepted: November 2, 2020; Published: November 27, 2020

\begin{abstract}
In order to improve the performance of the catalyst applied in ozonation, this work show the hydrothermal synthesis routine to prepare $\mathrm{MnO}_{2}$ with different oxygen vacancy content. The $\alpha-\mathrm{MnO}_{2}$ was aminated and further processed with doped graphene oxide $(\mathrm{GO})$ to obtain high oxygen vacancy content $\alpha-\mathrm{MnO}_{2}-\mathrm{NH}_{2}-\mathrm{GO}$, which was subsequently used for catalyzing ozonation phenol degradate. The catalysts were characterized by X-ray diffraction (XRD), X-ray photoelectron spectra (XPS), Brunner-Emmet-Teller (BET), $\mathrm{H}_{2}$-temperature-programmed reduction $\left(\mathrm{H}_{2}\right.$-TPR), scanning electron microscopy (SEM), etc. Characterization and experimental results showed that the oxygen vacancy content has an important effect on the catalytic performance of the catalyst, $\mathrm{MnO}_{2}$ with low average oxidation state showed better catalytic ozonation performance. The coexistence of $\mathrm{Mn}^{3+}$ and $\mathrm{Mn}^{4+}$ have great significant role for the continuous generation of free radicals and the restoration of oxygen vacancies. The doping of GO can increase the electron transfer rate, and improve the catalytic performance. The catalytic performance of $\alpha-\mathrm{MnO}_{2}-\mathrm{NH}_{2}-\mathrm{GO}$ is better than $\alpha-\mathrm{MnO}_{2}$, phenol removal rate can achieve more than $99 \%$ within 30 min, and superoxide radicals can be determined by different free radical trapping agents. The results of main active oxygen and reaction kinetics research showed that the degradation of phenol is a first-order reaction whether $\alpha-\mathrm{MnO}_{2}-\mathrm{NH}_{2}-\mathrm{GO}$ or $\alpha-\mathrm{MnO}_{2}$ is used as a catalyst.
\end{abstract}

Keywords: $\mathrm{MnO}_{2}$, Catalyst, Oxygen Vacancy, Ozonation, Phenol

\section{Introduction}

As one of the most severe pollution problems in the $21 \mathrm{st}$ century, water pollution seriously restricts the healthy and stable development of human society. Phenol is a representative aromatic hydrocarbon derivatives, which is one of the components of numerous bactericides, antibiotics and other drugs [1]. Phenol has a hydrophilic functional group, which has higher water solubility than its ring analogues and easily accumulates in water environment. It is noticed that phenol and its derivatives account for $27.4 \%$ of organic pollutants in coal gasification wastewater [2]. Phenol inhibits the growth of microorganisms by affecting the degradation process. Due to its toxicity, carcinogenicity and multi-sources, once released into the environment, phenol poses a great threat to plants, animals and humans so an effective method is urgently needed to degrade organic contaminants [3].

In recent years, advanced oxidation process technologies (AOPs) have been applied to phenol-containing wastewater treatments, such as $\mathrm{O}_{3} / \mathrm{UV}$, electrochemical oxidation, ultraviolet-photocatalytic oxidation, wet chemical oxidation, heterogeneous ozonation, etc. [4]. It is showed that homogeneous catalytic ozonation technology has some excellent characteristics such as suitable for high salinity system and no secondary pollution [5]. However, the problems of catalyst stability and ozone utilization rate have become important constraints for the further application of this technology. 
The oxide of a series of transition metals such as manganese [6], iron [7], copper [8], cobalt [9], nickel [10], etc. are mostly used in catalytic ozonation degradation of organic pollutants in wastewater. In particular, manganese dioxide, as an excellent heterogeneous catalytic ozonation catalyst, has received increasingly attention in industrial production and scientific research. In the current research on $\mathrm{MnO}_{2}$ catalytic ozonation of pollutants in water, more attention has been paid to the crystal form of catalyst. The directional growth of the crystal form can be achieved by adjusting the synthesis conditions of catalyst, but the substantial research on the influence of the crystal form on the catalytic oxidation process was very limited. In addition, the reaction between organics, ozone, and solid catalysts in water is a complex multiphase flow reaction. It is necessary to study the reaction mechanism of catalytic oxidation in depth, to better guide the synthesis of catalysts and the application of catalytic oxidation technology. As a special case of free radical theory, oxygen vacancy theory mainly uses a large number of lattice defects of metal oxides to affect the decomposition pathway of ozone, which in turn affects the generation of active free radicals. Many research results have proved that the content of oxygen vacancies has an important impact on the catalytic performance of the catalyst $[11,12]$. Previous experimental studies and theoretical calculations have shown that abundant oxygen vacancies can promote the rapid adsorption and activation of $\mathrm{O}_{3}$ molecules, increase the storage capacity of oxygen, and reduce the activation energy of oxygen migration [13-15].

In this paper, $\mathrm{MnO}_{2}$ with different crystal forms was synthesized by hydrothermal synthesis method, and $\alpha-\mathrm{MnO}_{2}$ with larger surface area, more active sites and higher oxygen vacancy content. It was successively subjected to amination and doped graphene (GO) treatment respectively, to improve the stability of the catalyst and the electron transmission efficiency in the reaction process. This thesis applied XRD characterization to determine the crystal form of various products. XPS technology to characterize and analyze the surface composition and chemical state of the catalyst. Further, via peak-divide the $\mathrm{Mn}_{2 \mathrm{P} 2 / 3}$ peak to analyze the valence information of Mn. Quantitative calculations and peak splitting of the $\mathrm{O}_{1 \mathrm{~s}}$ peak can quantitatively calculate the content of lattice oxygen and adsorbed oxygen in the catalyst. Phenol is used as the degradation target pollutant for catalytic ozonation, the effect of lattice oxygen and oxygen vacancy on catalytic oxidation reaction are verified by the experimental results.

\section{Materials and Methods}

\subsection{Materials}

The chemicals used in this work are all analytical grader or above: potassium permanganate, phenol, manganese sulfate, manganese acetate, 3-aminopropyltriethoxysilane, graphene, toluene and ethanol, etc.

\subsection{Catalyst Preparation}

Three different crystal forms of manganese dioxide were prepared by hydrothermal synthesis method. $\mathrm{KMnO}_{4}$ and $\mathrm{MnSO}_{4} \cdot \mathrm{H}_{2} \mathrm{O}$ were mixed with molar ratio of 5:5 and stirred for $20 \mathrm{~min}$ at room temperature with $70 \mathrm{~mL}$ deionized water, then the above solution was transferred to a $100 \mathrm{~mL}$ hydrothermal reactor to react for $12 \mathrm{~h}$ at $140^{\circ} \mathrm{C}$. The product was washed with deionized water until the solution was neutral, then dried at $105^{\circ} \mathrm{C}$ for $24 \mathrm{~h}$ to obtain $\alpha-\mathrm{MnO}_{2}$ (JCPDS no. 44-0141). The mixture of $\mathrm{KMnO}_{4}$ and $\mathrm{MnSO}_{4} \cdot \mathrm{H}_{2} \mathrm{O}$ was adjust ratio to $3: 7$, preparing $\beta-\mathrm{MnO}_{2}$ (JCPDS no. 24-0735) with similar experimental steps. $5.04 \mathrm{~g} \mathrm{KMnO}_{4}$ and $7.82 \mathrm{~g} \mathrm{Mn}\left(\mathrm{CH}_{3} \mathrm{COO}\right)_{2}$, same as above experiment operation to obtain $\gamma-\mathrm{MnO}_{2}$ (JCPDS no. 44-1386). $\alpha-\mathrm{MnO}_{2}$ was mixed with a certain proportion of graphene. After drying, the mixture was reacted with $50 \mathrm{~mL}$ of toluene in $80^{\circ} \mathrm{C}$ water bath for $6 \mathrm{~h}$. During reaction, the $5 \mathrm{~mL}$ of 3 -aminopropyltriethoxysilane was added dropwise. The catalyst was obtained by drying at $105^{\circ} \mathrm{C}$ overnight and was named $\alpha-\mathrm{MnO}_{2}-\mathrm{NH}_{2}-\mathrm{GO}$.

\subsection{Catalytic Oxidation Experiment}

The self-assembled catalytic ozonation device was used to test the performance of the catalyst, the flow chart is shown in Figure 1. The phenol solution was used as the feed $\left(C_{0}=50\right.$ $\mathrm{mg} / \mathrm{L}$ ), and the concentration of $20 \mathrm{mg} / \mathrm{L}$ ozone was provided by an ozone generator with oxygen source. The ozone flow was controlled to $0.1 \mathrm{~L} / \mathrm{min}$ by mass flow meter, the catalyst dosage was $0.2 \mathrm{~g} / \mathrm{L}$ and recycled. The reaction was carried out for $30 \mathrm{~min}$ under stirring and samples were taken at certain intervals. The water sample was filtered through a $0.45 \mu \mathrm{m}$ microporous filter membrane and analyzed by high performance liquid chromatography (HPLC), which was equipped with an ultraviolet detector to detect the residual phenol concentration. The testing method was as follows: the mobile phase was a methanol solution containing $1 \%$ acetic acid $\left(V_{\text {methanol }}: V_{\text {water }}=6: 4\right)$, with $1 \mathrm{~mL} / \mathrm{min}$ flow rate and $10 \mu \mathrm{L}$ injection volume. The detector wavelength was set to $313 \mathrm{~nm}$.

\subsection{Catalyst Characterization}

The structure and phase of the catalyst were analyzed by X-ray diffraction (XRD, Japanese Science Group Corporation $\mathrm{D} / \mathrm{max}-2500 / \mathrm{PC}$ ), operating at an accelerated voltage of $40 \mathrm{kV}$ and an emission current of $40 \mathrm{~mA}$ with $\mathrm{Cu} \mathrm{K \alpha}$ radiation. The $2 \theta$ was measured between $10^{\circ}-80^{\circ}$ in the step of $0.01^{\circ} / \mathrm{s}$. The surface area and pore size analysis by $\mathrm{N}_{2}$ adsorption/desorption (Micromeritics ASAP2460), the sample was degassed under vacuum at $350^{\circ} \mathrm{C}$ for $5 \mathrm{~h}$, according to the BET equation in the range of $10^{-5}-0.999 \mathrm{P} / \mathrm{P}_{0}$. Surface morphology of the sample was observed by scanning electron microscope (SEM, Zeiss GEMINISEM 500) with an acceleration voltage of $0.02-30 \mathrm{kV}$. X-ray photoelectron spectroscopy (XPS, Physical Electronics Corporation PHI5300-Type) was used to analyze the elements and their valence information on the catalyst surface, the data was processed by XPS-PEAK software for peak splitting, the molar ratio of elements was determined by the area ratio after 
splitting. $\mathrm{H}_{2}$-temperature-programmed reduction $\left(\mathrm{H}_{2}-\mathrm{TPR}\right)$ was carried on an Auto Chem II 2920 (Micromeritics, USA) with $10 \mathrm{vol} \% \mathrm{H}_{2}$ in $\mathrm{Ar}$, and at a step of $5^{\circ} \mathrm{C} / \mathrm{min}$ to detect the absorption peak in the range of $50-800^{\circ} \mathrm{C}$.

\section{Results and Discussion}

\subsection{Structural of Synthetic Materials}

Different preparation conditions and the ratio of reactants will cause significant difference in $\mathrm{MnO}_{2}$ crystal and surface chemical state. The XRD patterns and crystal structure of the three obtained $\mathrm{MnO}_{2}$ and the catalyst $\left(\alpha-\mathrm{MnO}_{2}-\mathrm{NH}_{2}-\mathrm{GO}\right)$ are shown in Figure 1. According to the composition of $\mathrm{MnO}_{2}$ crystals, the connection of the basic structural unit $\mathrm{MnO}_{6}$ octahedron was the main reason for the difference within various crystal structures. These three types of $\mathrm{MnO}_{2}$ all belong to the tunnel structure. A large number of researchers showed that $\alpha-\mathrm{MnO}_{2}$ was $(2 \times 2)$ tunnel structure, $\beta-\mathrm{MnO}_{2}$ and $\gamma-\mathrm{MnO}_{2}$ are respectively $(1 \times 1)$ and $(2 \times 1)$ tunnel structure. $2 \times 2$ tunnel structure can not only effectively increase the surface area of catalyst and the number of active sites, but also contribute to the adsorption of organic on the surface of the catalyst, in which adsorption was an important step in the catalytic reaction. Thus, the larger pore structure can be conducive to the improvement of the catalytic effect. The diffraction peaks in the $\alpha-\mathrm{MnO}_{2}$ diffraction pattern are significantly broadened, indicating that its poor crystallinity was beneficial for exposing more active sites. The higher crystallinity of $\beta-\mathrm{MnO}_{2}$ will increase the impedance within the catalyst which was not conducive to the reaction. In addition, the strength of the Mn-O bond in the different crystalline nano- $\mathrm{MnO}_{2}$ was quite different. The $\mathrm{Mn}-\mathrm{O}$ binding force of $\beta-\mathrm{MnO}_{2}$ among three types of $\mathrm{MnO}_{2}$ crystalline is the largest and most difficult to break down, resulting in its poor lattice oxygen flow so its catalytic activity is also the lowest.

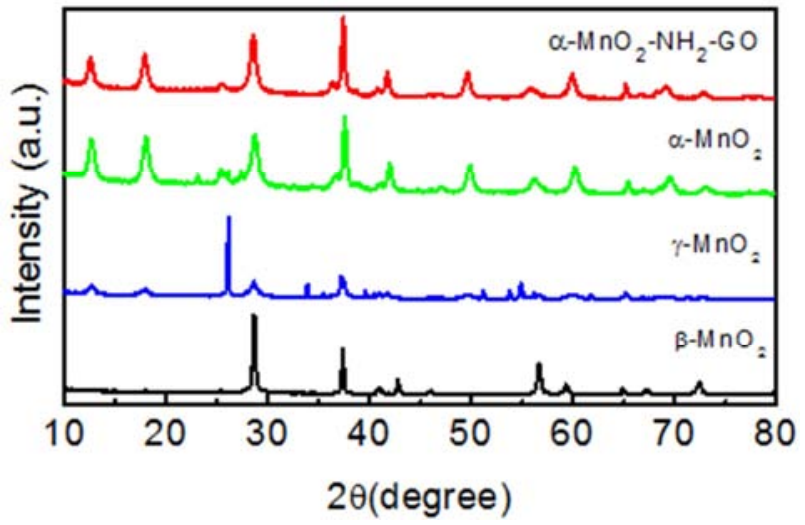

Figure 1. XRD patterns of different crystal forms of $\mathrm{MnO}_{2}$.

In addition, according to the characterization results, the crystal of $\alpha-\mathrm{MnO}_{2}-\mathrm{NH}_{2}-\mathrm{GO}$ is completely consistent with $\alpha-\mathrm{MnO}_{2}$, indicating that the crystal form of $\mathrm{MnO}_{2}$ has not been destroyed during the preparation process. Yang et al. [16] used potassium permanganate and manganese acetate as precursors to synthesize $\alpha-\mathrm{MnO}_{2}$ catalysts. The experimental results show that the catalytic ozone degradation experiment is more effective, but the manganese sulfate precursor used in this work is cheaper, so the content of this study has better economic benefits. Tan et al. [17] also found in experiments that the catalytic performance of $\alpha-\mathrm{MnO}_{2}$ is better than that of $\delta-\mathrm{MnO}_{2}$, mainly because the former has more abundant surface oxygen species.

\subsection{Surface Area and Pore Size of Synthetic Materials}

The solid catalyst used for catalytic ozone oxidation meets at least one of the following three conditions:

(1) Ozone molecules can be easily adsorbed on the surface of the catalyst;

(2) Organic matter can be adsorbed on the surface of the catalyst;

(3) Both ozone and organic matter can be simultaneously adsorbed on the surface of the catalyst.

It can be seen that the adsorption of substances in the heterogeneous catalytic reaction is the basis of the reaction, which requires the catalyst to provide a larger specific surface area and more active sites. Figure 2 is the $\mathrm{N}_{2}$ adsorption-desorption isotherm and pore size distribution diagram of four materials. From characterization results, it can be seen that the adsorption-desorption isotherms of the materials are all shown as $\mathrm{H} 3$ type hysteresis ring type IV isotherms. It can be seen that all the four materials are mesoporous materials with uneven pore size distribution. The large pore channels in the mesoporous materials can facilitate the entry of organic matter in the catalytic reaction, while some small pores can provide abundant active sites, and the interactive distribution of pores with different pore size can facilitate the smooth progress of the catalytic reaction. The surface area order of three prepared $\mathrm{MnO}_{2}$ are: $\alpha-\mathrm{MnO}_{2}\left(41.50 \mathrm{~m}^{2} / \mathrm{g}\right)>\gamma-\mathrm{MnO}_{2}(33.85 \mathrm{~m} / \mathrm{g})>\beta-\mathrm{MnO}_{2}$ $\left(14.25 \mathrm{~m}^{2} / \mathrm{g}\right)$, which is mainly due to the larger tunnel structure under the same quality provides more specific surface area. The average pore size of the three types is $\alpha-\mathrm{MnO}_{2}(26.3 \mathrm{~nm})>\gamma-\mathrm{MnO}_{2}(22.43 \mathrm{~nm})>\beta-\mathrm{MnO}_{2}(17.26$ $\mathrm{nm})$, these data results also prove the above conclusion related to tunnel structure. Mo et al. [18] prepared spherical $\mathrm{MnO}_{2}$ as a catalyst. In the experiment of catalyzing the degradation of organic matter, the average pore diameter of the catalyst was only $7.1 \mathrm{~nm}$, which was much smaller than the catalyst prepared by the hydrothermal method in this work. The larger pores were not conducive to the progress of the catalytic reaction. A suitable hydrothermal environment is conducive to the growth of crystals.

Comparing the surface area and pore size of $\alpha-\mathrm{MnO}_{2}$ with $\alpha-\mathrm{MnO}_{2}-\mathrm{NH}_{2}-\mathrm{GO}$, we can find that the surface area of $\alpha-\mathrm{MnO}_{2}$ increases from $41.5 \mathrm{~m}^{2} / \mathrm{g}$ to $74.4 \mathrm{~m}^{2} / \mathrm{g}$ with increasing rate $79.3 \%$. The average pore diameter of the material decreases from $26.3 \mathrm{~nm}$ to $13.0 \mathrm{~nm}$, and the pore size distribution diagram compared with the $\alpha-\mathrm{MnO}_{2}$ pore size distribution diagram, $\alpha-\mathrm{MnO}_{2}-\mathrm{NH}_{2}-\mathrm{GO}$ showed a higher proportion of micropore structure. This result might because the functional groups on the graphene surface 
occupy some of the pores during the doping process of graphene or the bridging effect of $-\mathrm{NH}_{2}$ during the amination process causes some pores to be blocked and larger pores to be divided into multiple smaller pores, resulting in an increase in surface area and a significant decrease in pore size.

The atomic composition test of the materials before and after amination by XPS is shown in Table $1 \mathrm{~K} / \mathrm{Mn}$ in $\alpha-\mathrm{MnO}_{2}$ is 0.114 but in $\alpha-\mathrm{MnO}_{2}-\mathrm{NH}_{2}-\mathrm{GO}$ after amination is only 0.06 , which shows that the amination treatment makes $47 \%$ of $\mathrm{K}^{+}$escapes. Meanwhile, Figure 5 shows that the absorption peak of $\mathrm{N}$ element appears after amination, which also shows that parts of $\mathrm{NH}_{4}^{+}$may enter into the channel of $\mathrm{MnO}_{2}$ instead of $\mathrm{K}^{+}$during amination process. The $\mathrm{K}^{+}$ions in the $\mathrm{MnO}_{2}$ tunnels not only compensated the charge imbalance, but also combined the two channels together. Some $\mathrm{K}^{+}$ions even coordinated with $\mathrm{O}$ atoms in Mn vacancies. Therefore, the $\mathrm{K}^{+}$in the tunnel is considered to stabilize the tunnel structure. The stable crystal structure is not easy to produce lattice defects, so less likely to expose more active sites. At the same time, $\mathrm{K}^{+}$enters the lattice to balance the charge and also occupy the sites of oxygen vacancies, resulting in a decrease in the content of oxygen vacancies. Therefore, the amino group chemical treatment can effectively increase the oxygen vacancy content of the catalyst [19].

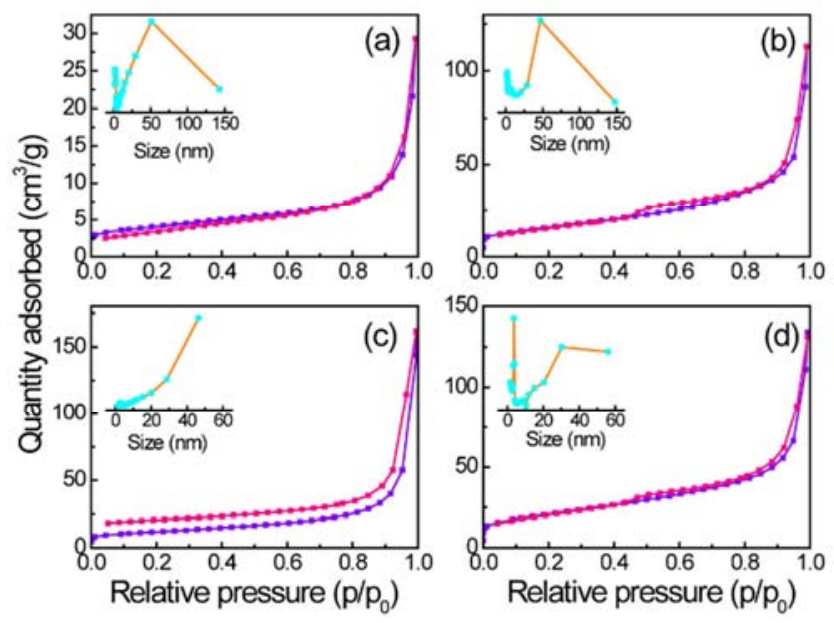

Figure 2. $N_{2}$ adsorption-desorption isotherm and pore size distribution of (a) $\beta-\mathrm{MnO}_{2}$, (b) $\gamma-\mathrm{MnO}_{2}$, (c) $\alpha-\mathrm{MnO}_{2}$ and (d) $\alpha-\mathrm{MnO}_{2}-\mathrm{NH}_{2}-\mathrm{GO}$.

Table 1. The surface area and pore volume of the four synthetic materials.

\begin{tabular}{lllll}
\hline Catalyst & Surface area $\left(\mathbf{m}^{\mathbf{2}} \mathbf{g}^{-1}\right)$ & Pore volume $\left(\mathbf{c m}^{\mathbf{3}} \mathbf{g}^{-\mathbf{1}}\right)$ & Pore size $(\mathbf{n m})$ & K: Mn ration \\
$\alpha-\mathrm{MnO}_{2}$ & 41.50 & 0.135 & 26.30 & 0.114 \\
$\gamma-\mathrm{MnO}_{2}$ & 33.85 & 0.095 & 22.43 & - \\
$\beta-\mathrm{MnO}_{2}$ & 14.25 & 0.021 & 17.26 & - \\
$\alpha-\mathrm{MnO}_{2}-\mathrm{NH}_{2}-\mathrm{GO}$ & 74.37 & 0.120 & 13.00 & 0.060 \\
\hline
\end{tabular}

\subsection{Redox Capacity of Synthetic Materials}

$\mathrm{H}_{2}$-temperature-programmed reduction $\left(\mathrm{H}_{2}-\mathrm{TPR}\right)$ characterization is an effective tool to study the reducing capacity of solid oxide catalysts. Better low-temperature reducibility is usually conducive to enhancing the fluidity of oxygen, thereby promoting the redox process [20]. It can be seen from Figure 3 that $\alpha-\mathrm{MnO}_{2}$ has two reduction absorption peaks at $341.9^{\circ} \mathrm{C}$ and $536.9^{\circ} \mathrm{C}$, respectively. The reduction adsorption curves of $\gamma-\mathrm{MnO}_{2}$ and $\alpha-\mathrm{MnO}_{2}$ are basically the same, but the two reduction peaks of $\gamma-\mathrm{MnO}_{2}$ located at $351.3^{\circ} \mathrm{C}$ and $525.6^{\circ} \mathrm{C}$ respectively. The first absorption peak of $\gamma-\mathrm{MnO}_{2}$ obviously shifted to the high temperature, indicating that the mobile phase change of its surface oxygen is poor. The peak temperature of $\beta-\mathrm{MnO}_{2}$ is $362.9^{\circ} \mathrm{C}$, which is higher than the former two and its absorption peak has larger area. This also proves that the bonding force of $\mathrm{Mn}-\mathrm{O}$ in $\beta-\mathrm{MnO}_{2}$ is the largest. Therefore, the poor oxygen fluidity on $\beta-\mathrm{MnO}_{2}$ surface leads to the decrease of oxygen vacancy content on the catalyst surface. According to the redox theory, high-valent metal ions in metal oxides will be reduced to low-valent ions, so $\mathrm{MnO}_{2}$ will be reduced to $\mathrm{Mn}_{3} \mathrm{O}_{4}$ or $\mathrm{Mn}_{2} \mathrm{O}_{3}$ or even $\mathrm{MnO}$. From the perspective of reaction kinetics to interpret, indicates that the oxide is easier to be reduced, and the catalyst contains more abundant loose-structured surface oxygen species. The reducibility sequence of the three crystalline forms of manganese dioxide can be deduced as follows: $\alpha-\mathrm{MnO}_{2}>\gamma-\mathrm{MnO}_{2}>\beta-\mathrm{MnO}_{2}$, specific amount of hydrogen consumed shown in Table 1 . This conclusion is also consistent with the XPS characterization results, in which the average valence sequence of the $\mathrm{Mn}$ elements in the three crystalline oxides is: $\alpha-\mathrm{MnO}_{2}<\gamma-\mathrm{MnO}_{2}<\beta-\mathrm{MnO}_{2}$. According to the principle that the oxygen vacancy can balance the charge non-conservation in the compound, it can be inferred that $\alpha-\mathrm{MnO}_{2}$ has a higher oxygen vacancy content. The comparison between $\alpha-\mathrm{MnO}_{2}$ and $\alpha-\mathrm{MnO}_{2}-\mathrm{NH}_{2}-\mathrm{GO}$ shows that the total hydrogen consumption of $\alpha-\mathrm{MnO}_{2}-\mathrm{NH}_{2}-\mathrm{GO}$ is much smaller than the former and the reduction peak position is also more complicated, which indicated that the amination and doping of graphene could reduce the metal valence and increase the oxygen vacancy of the catalyst. It also shows that the surface properties of the catalyst have changed greatly after doping modification. Hu et al. [21] mentioned in the literature reviewing the preparation of manganese dioxide composite graphene catalysts that directly mixing potassium permanganate with GO will destroy the structure and properties of $\mathrm{GO}$ itself. In this paper, manganese dioxide is synthesized first and then doped. The preparation of composite catalyst can effectively avoid the problem of the destruction of GO's functional groups. 


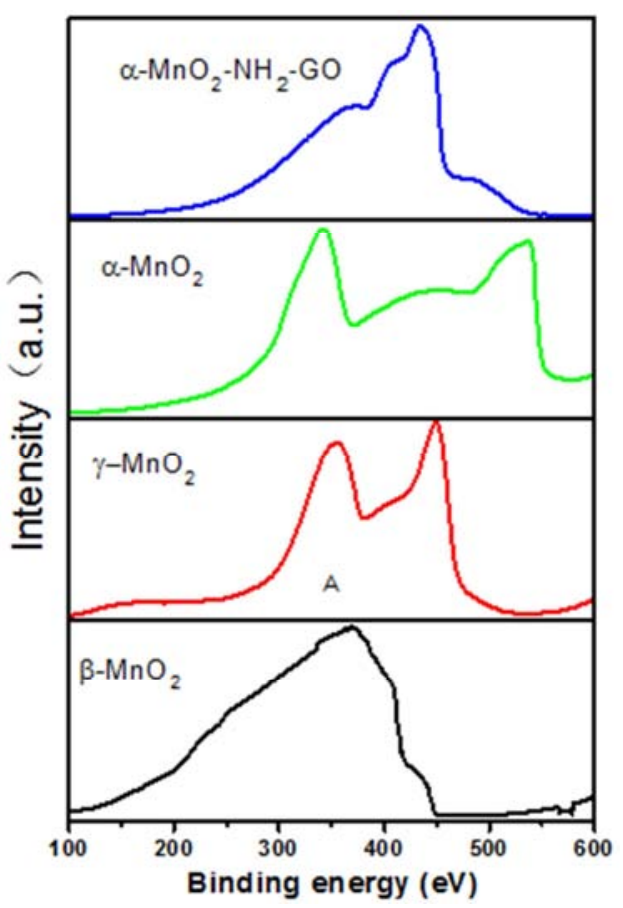

Figure 3. $H_{2}-T P R$ diagram of the catalyst.

\subsection{Micro-morphology of Synthetic Materials}

In addition to the surface acid-base property and surface functional groups, the morphology of the catalytic material will also have a greater impact on its catalytic performance, so the control of the morphology of synthetic materials has also become an important project in the direction of nanomaterial synthesis. Through certain experimental conditions and experimental methods, different active crystal planes of the catalyst can be selectively exposed to generate more active sites to improve material properties. SEM shows that the different crystal forms of $\mathrm{MnO}_{2}$ are fibrous, but $\alpha-\mathrm{MnO}_{2}$ is relatively uniformly dispersed and short needle-shaped; while $\gamma-\mathrm{MnO}_{2}$ has a long fibrous structure of uneven thickness and a partial network structure superposition to some extent, which will lead to the reduction of specific surface area of the catalyst and the reduction of active sites. $\beta-\mathrm{MnO}_{2}$ shows a thicker and alternately overlapping thick fibers, which is mutually confirmed with the test results of the specific surface area, once again proving that $\alpha-\mathrm{MnO}_{2}$ can expose more active sites and effectively promote ozone decomposition to generate active radicals. It can be clearly seen from the SEM picture of $\alpha-\mathrm{MnO}_{2}-\mathrm{NH}_{2}-\mathrm{GO}$ (Figure 4) that a large number of fine needle-like substances are loaded on the surface of the large particles in the network structure. The surface of $\mathrm{MnO}_{2}$ is successfully loaded on the surface of graphene, on the one hand, it is related to the bridging effect of $-\mathrm{NH}_{2}$; on the one hand, the interaction between functional groups on the surface of $\mathrm{MnO}_{2}$ and functional groups on the surface of graphene will also enable $\mathrm{MnO}_{2}$ to be successfully loaded on the catalyst surface through bonding and interaction. The doping of graphene can provide more abundant surface oxygen-containing functional groups, the SEM image of GO shown in Figure 5, and the surface oxygen-containing functional groups are often the starting point of a chain reaction that generates free radicals. After a large number of literature investigations, He et al. [21] found that 3D graphene has better properties than the network graphene used in this article. 3D graphene not only maintains the excellent properties of graphene, but also enhances the practical application potential of graphene and can effectively prevent. It is easy to operate and separate in practical applications, and can prevent the release of graphene sheets and its environmental risks. Therefore, in the future experiments of graphene composite manganese dioxide catalyzed organic degradation, the use of three-dimensional graphene can be tried.
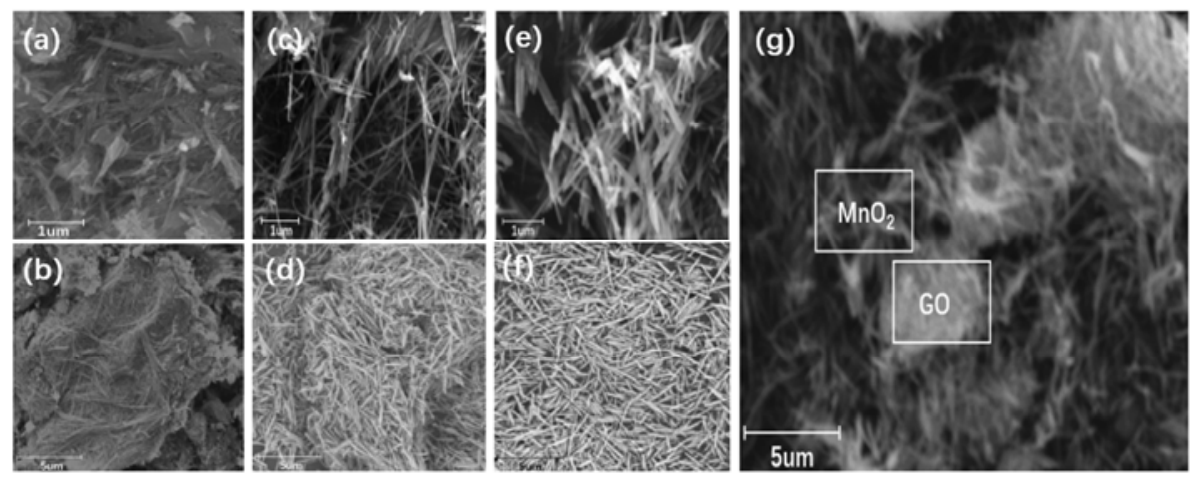

Figure 4. SEM pictures of $\beta-\mathrm{MnO}_{2}(a-b) \gamma-\mathrm{MnO}_{2}(c-d) \alpha-\mathrm{MnO}_{2}(e-f)$ and $\alpha-\mathrm{MnO}_{2}-\mathrm{NH}_{2}-\mathrm{GO}(g)$.

Comparing the XPS spectra of $\alpha-\mathrm{MnO}_{2}$ and $\alpha-\mathrm{MnO}_{2}-\mathrm{NH}_{2}-\mathrm{GO}$ (Figure 5), it can be found that $\alpha-\mathrm{MnO}_{2}-\mathrm{NH}_{2}-\mathrm{GO}$ has a characteristic absorption peak of $\mathrm{N}_{1 \mathrm{~S}}$ at the position where the binding energy is $405 \mathrm{eV}$. It is proved that the $\mathrm{N}$ appears in the sample, so the process of amination is successful, which is confirmed by the successful loading in the scanning electron microscopy picture of the catalyst. It once again proves that $-\mathrm{NH}_{2}$ can play a bridging role, which helps to improve the stability of the catalyst. Song et al. [22] prepared graphene $/ \mathrm{MnO}_{2}$ composite $\mathrm{MnO}_{2}$ catalyst graphene $/ \mathrm{MnO}_{2}$. In their research on degradation of tetracycline, they found that the performance of the catalyst largely depends on the $\mathrm{pH}$ value of the reaction system, that is, the stability and applicability of the catalyst is poor. This work can effectively improve the binding strength of manganese dioxide and GO through 
amination modification.

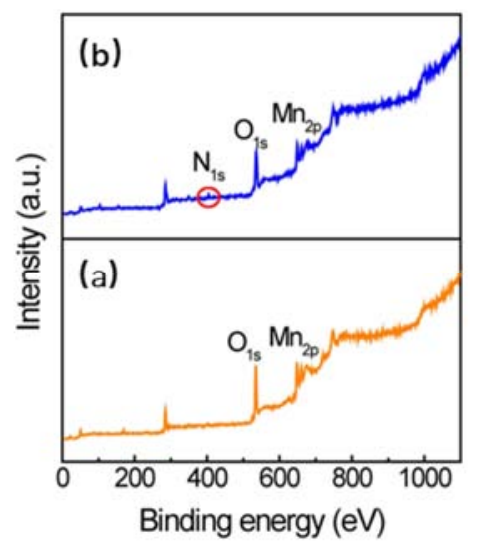

Figure 5. XPS spectrum of $\alpha-\mathrm{MnO}_{2}(a)$ and $\alpha-\mathrm{MnO}_{2}-\mathrm{NH}_{2}-\mathrm{GO}$ (b).

\subsection{Surface Chemical State Analysis of Synthetic Materials}

Using XPS to analyze the valence electron state of the material, the characterization results are shown in Figure 6. The peak binding energies of $\mathrm{Mn}_{2 \mathrm{p} 3 / 2}$ are $641.9-641.8 \mathrm{eV}$ and 642.8-643.0 eV, which can be attributed to $\mathrm{Mn}^{3+}$ and $\mathrm{Mn}^{4+}$, respectively. The results of quantitative calculation and analysis of the characterization results show that the $\mathrm{Mn}^{3+} / \mathrm{Mn}^{4+}$ molar ratio of the three materials is ranked as follows: $\alpha-\mathrm{MnO}_{2}(0.81)>\gamma-\mathrm{MnO}_{2}(0.61)>\beta-\mathrm{MnO}_{2}(0.43)$. A large amount of literature shows that the coexistence of $\mathrm{Mn}^{3+}$ and $\mathrm{Mn}^{4+}$ can facilitate the transfer of electrons in the redox process, the electron transfer process can achieve oxygen vacancy and the conversion of lattice oxygen which is conducive to the generation of free radicals such as $\cdot \mathrm{OH}$ and improves the efficiency of catalytic oxidation [23-25]. According to the principle of electrostatic conservation, the presence of $\mathrm{Mn}^{3+}$ in $\mathrm{MnO}_{2}$ means the presence of oxygen vacancies, that is, the higher content of $\mathrm{Mn}^{3+}$ on the surface indicates the higher content of oxygen vacancies. It can be seen that the order of the oxygen vacancy content in different crystal types of $\mathrm{MnO}_{2}$ is $\alpha-\mathrm{MnO}_{2}>\gamma-\mathrm{MnO}_{2}>\beta-\mathrm{MnO}_{2}$, the generation of oxygen vacancies can facilitate the flow of lattice oxygen and enhance the electron transport efficiency during the redox reaction [26].

The peaks of $\mathrm{O}_{1 \mathrm{~s}}$ spectra of all samples were analyzed as shown in Figure 7. The binding energy is $529.5-529.7 \mathrm{eV}$, which is attributed to lattice oxygen $\left(\mathrm{O}_{\mathrm{I}}\right)$, and the binding energy is $531.0-531.2 \mathrm{eV}$, which is indicative of adsorbed oxygen $\left(\mathrm{O}_{\text {III }}\right)$. It shows that the order of $\mathrm{O}_{\text {II }} / \mathrm{O}_{\mathrm{I}}$ molar ratio is: $\alpha-\mathrm{MnO}_{2}(0.56)>\gamma-\mathrm{MnO}_{2}(0.50)>\beta-\mathrm{MnO}_{2}$ (0.47). Comparing the data of $\alpha-\mathrm{MnO}_{2}$ with the treated $\alpha-\mathrm{MnO}_{2}-\mathrm{NH}_{2}-\mathrm{GO}$, the diagram shows that the value of the latter $\mathrm{Mn}^{3+} / \mathrm{Mn}^{4+}$ is 0.74 , which is significantly lower than that of $\alpha-\mathrm{MnO}_{2}(0.81)$. The peak separation result of the $\mathrm{O}_{1 \mathrm{~s}}$ spectrum appears new peak at the binding energy of $533.6 \mathrm{eV}$, it shows that the peak can be attributed to the surface adsorbed water peak, which is named $\mathrm{O}_{\text {III }}$, and the $\mathrm{O}_{\mathrm{II}} / \mathrm{O}_{\mathrm{I}}$ molar ratio of $\alpha-\mathrm{MnO}_{2}-\mathrm{NH}_{2}-\mathrm{GO}$ is reduced from 0.56 of $\alpha-\mathrm{MnO}_{2}$ to 0.51 .

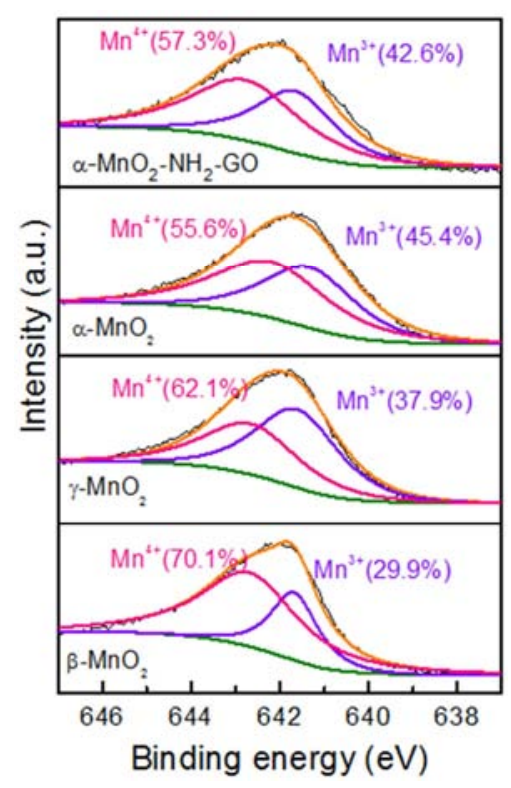

Figure 6. Mn $2 p$ XPS spectra of different catalyst.

Oxygen adsorption is the formation of oxygen vacancy adsorbed by oxygen molecules on the surface of metal oxides, so the oxygen content on the surface can represent the oxygen vacancy content on the surface of metal oxides. Compared with $\alpha-\mathrm{MnO}_{2}$, the main reason for the decrease in oxygen vacancies content in $\alpha-\mathrm{MnO}_{2}-\mathrm{NH}_{2}-\mathrm{GO}$ catalyst probably because some redox reactions happened during the reaction with amination and doping of graphene, leading to $\mathrm{Mn}^{3+}$ / $\mathrm{Mn}^{4+}$ and $\mathrm{O}_{\mathrm{II}} / \mathrm{O}_{\mathrm{I}}$ value drop. Yu et al. [27] studied the reaction mechanism of catalytic oxidation of organics in water, they also proposed that the oxygen vacancy content has a strong correlation with the performance of the catalyst. In this paper, a hydrothermal synthesis method is used to prepare a highly efficient catalyst with high oxygen vacancy content. Meaningful work.

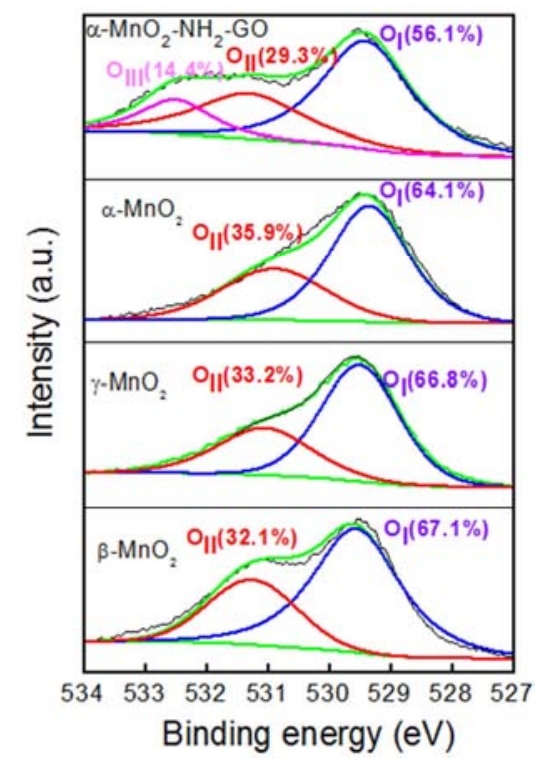

Figure 7. $O_{I S} X P S$ spectra of different catalyst. 


\subsection{Catalytic Ozonation of Phenol}

Under certain experimental conditions, catalytic oxidation experiments were carried out on a phenol solution with an initial concentration of $50 \mathrm{mg} / \mathrm{L}$. As Figure 8 shown, the concentration of phenol was determined by HPLC at fixed intervals, Figure 3 was the fitting curve of the standard samples tested by HPLC. It can be seen from the experimental results that the different catalysts for ozonation have a certain catalytic effect and the different catalysts show a large performance difference after 30 minutes of reaction. Among the three crystalline of $\mathrm{MnO}_{2}$, after 30 minutes of reaction, the catalytic effect of $\alpha-\mathrm{MnO}_{2}$ is the best with a phenol degradation efficiency achieving to $95.8 \%$; followed by the catalytic effect of $\gamma-\mathrm{MnO}_{2}$ with a phenol degradation efficiency of $93.6 \%$; and lastly the catalytic effect of $\beta-\mathrm{MnO}_{2}$ with phenol degradation efficiency of $90.6 \%$, which has the worst performance, Figure 4 show specific concentration value. Combined with the characterization results of the catalyst, it can be seen that $\alpha-\mathrm{MnO}_{2}$ contains the most surface oxygen and $\mathrm{Mn}^{3+} / \mathrm{Mn}^{4+}$ also indicates containing more oxygen vacancies, which will lead to the formation of more free radicals, thereby promoting the improvement of the catalytic effect. Comparing the catalytic effects of $\alpha-\mathrm{MnO}_{2}$ and $\alpha-\mathrm{MnO}_{2}-\mathrm{NH}_{2}-\mathrm{GO}$, it can be found that the explanation rate of phenol increased from $95.8 \%$ to $99.9 \%$ after 30 minutes, which may be significantly improved with the amination and doping of GO. On one hand, doping graphene can significantly increase the surface area of catalyst, increasing from $41.5 \mathrm{~m}^{2} \mathrm{~g}^{-1}$ to $74.37 \mathrm{~m}^{2} \mathrm{~g}^{-1}$; on the other hand, due to the bridging effect of $-\mathrm{NH}_{2}$, a new chemical bond is formed between $\mathrm{GO}$ and $\mathrm{MnO}_{2}$ making the two combined more closely, thereby improving the conduction rate of electrons between the two and the catalytic performance of the catalyst.

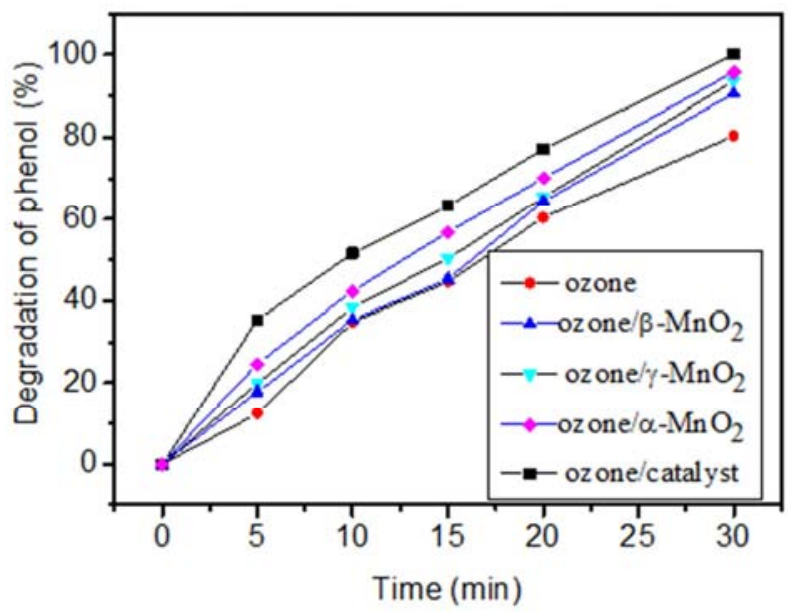

Figure 8. Time-dependent degradation of phenol Reaction condition: $\left[\right.$ phenol] ${ }_{0}=50 \mathrm{mg} / \mathrm{L},\left[\mathrm{O}_{3}\right]=4 \mathrm{mg} / \mathrm{min},[$ catalyst $]=0.2 \mathrm{~g} / \mathrm{L}$.

\subsection{Study on Reaction Mechanism and Reaction Kinetics}

The type of free radical has an important influence on the reaction effect. Therefore, the research on the determination of free radical type has become an important content in the study of heterogeneous catalytic ozone oxidation. P-Benquinone (p-BQ) is a typical superoxy radical $\left(\mathrm{O}_{2}^{-}\right)$quencher, which can react with superoxy radicals in water to consume superoxy radicals in water. Bicarbonate $\left(\mathrm{HCO}_{3}{ }^{-}\right)$and tert-butanol (t-BA) are typical hydroxyl radical $(\mathrm{OH})$ quenchers, which can react with hydroxyl radicals in water and consume hydroxyl radicals. Also, p-BQ, $\mathrm{HCO}_{3}{ }^{-}$and $\mathrm{t}-\mathrm{BA}$ are add $=\mathrm{d}$ into the reaction system respectively as free radical capture agents. The experimental results are shown in Figure 9, adding $50 \mathrm{mg} / \mathrm{L}$ of $\mathrm{HCO}_{3}{ }^{-}$and t-BA has almost no effect on the degradation of phenol, $\alpha-\mathrm{MnO}_{2}-\mathrm{NH}_{2}$-GO catalytic effect can reach more than $99 \%$. While adding $50 \mathrm{mg} / \mathrm{L}$ of $\mathrm{p}-\mathrm{BQ}$ significantly reduces the degradation of phenol by only about $80 \%$, which is almost consistent with the degradation effect of pure ozone. Above mentioned experimental data indicate that the main oxidation effect in the process of $\alpha-\mathrm{MnO}_{2}-\mathrm{NH}_{2}-\mathrm{GO}$ catalytic ozonation is $\mathrm{O}_{2}^{-}$, that is, the process of $\alpha-\mathrm{MnO}_{2}-\mathrm{NH}_{2}-\mathrm{GO}$ catalytic ozonation belongs to superoxy radical reaction. The formation mechanism of $\mathrm{O}_{2}{ }^{-}$and the oxidation pathways involved in organic are shown in equations (1)-(5). Combined with the theoretical analysis of oxygen vacancies above, it can be seen that the presence of $\mathrm{Mn}^{3+}$ is conducive to the generation of oxygen vacancies, and the presence of $\mathrm{Mn}^{3+}$ in equation (1) is also conducive to the formation of $\cdot \mathrm{O}_{2}^{-}$. Therefore, it can be deduced that the higher oxygen vacancy content is, the more favorable it is to the generation of superoxy radicals and the improvement of catalytic effect. Wang et al. [28] in an article reviewing the reaction mechanism of heterogeneous catalytic ozone oxidation. Proposed that there are still different opinions on the reaction mechanism of catalytic organic degradation. The study of active free radicals in this research proves that superoxy radicals are active oxygen. This result is different from most previous studies. The reaction mechanism is different in different heterogeneous catalytic reactions. However, there are few studies on reactive centers in this article, so further research is necessary for follow-up research work.

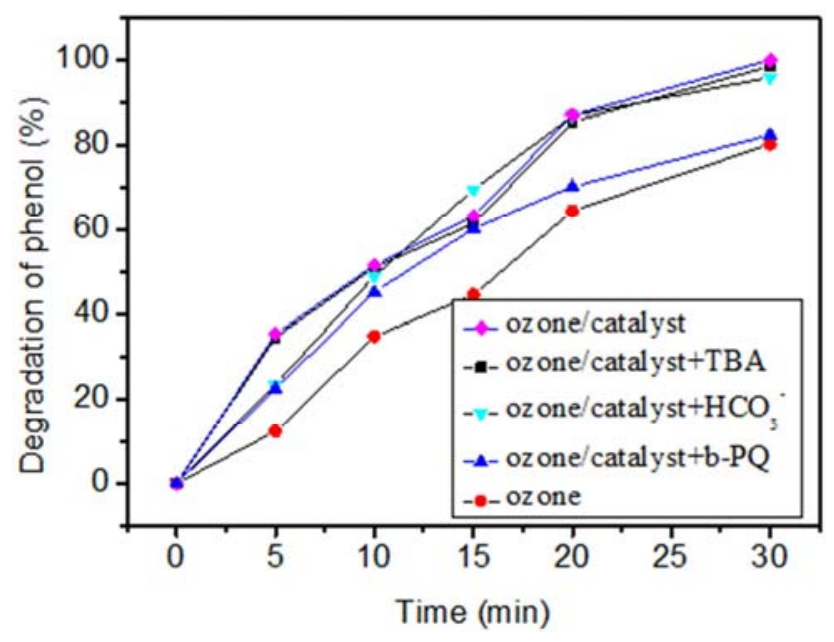

Figure 9. Catalytic ozonation of phenol with different catalysts in the presence of different scavengers. 


$$
\begin{gathered}
=\mathrm{Mn}^{3+}-\mathrm{OH}-\mathrm{O}_{3} \longrightarrow=\mathrm{Mn}^{4+}+\mathrm{O}_{2}-+\cdot \mathrm{HO}_{2} \\
2 \cdot \mathrm{O}_{2}-+2 \mathrm{H}^{+} \longrightarrow \mathrm{H}_{2} \mathrm{O}_{2}+{ }^{1} \mathrm{O}_{2} \\
\mathrm{O}_{2}-\text { +organics } \longrightarrow \mathrm{CO}_{2}+\mathrm{H}_{2} \mathrm{O} \\
{ }^{1} \mathrm{O}_{2}+\text { organics } \longrightarrow \mathrm{CO}_{2}+\mathrm{H}_{2} \mathrm{O} \\
2=\mathrm{Mn}^{4+}+\mathrm{O}_{\text {lat }}^{2-} \longrightarrow 2=\mathrm{Mn}^{3+}+1 / 2 \mathrm{O}_{2}
\end{gathered}
$$

HPLC was used to detect the phenol concentration in water samples taken at different time periods. The data analysis of concentrations at different time periods showed that the superoxide radical reactions catalyzed by $\alpha-\mathrm{MnO}_{2}$ and $\alpha-\mathrm{MnO}_{2}-\mathrm{NH}_{2}-\mathrm{GO}$ were both first-order reactions, and the degradation of phenol by ozonation was also first-order (Figure 10). However, the rate constant of ozonolysis of phenol degradation by $\alpha-\mathrm{MnO}_{2}-\mathrm{NH}_{2}-\mathrm{GO}$ is 0.099 , and the rate constants of pure ozone and $\alpha-\mathrm{MnO}_{2}$ are 0.042 and 0.061 , respectively, so the reaction rate of $\alpha-\mathrm{MnO}_{2}-\mathrm{NH}_{2}-\mathrm{GO}$ is 2.4 times that of pure ozone and 1.6 times that of $\alpha-\mathrm{MnO}_{2}$. This is mainly related to the doping of $\mathrm{GO}$, it with a network structure provides a huge surface area and can accelerate the electron transport rate, thereby speeding up the redox reaction rate. In addition, the oxygen vacancy content and the electron transport rate are also positively correlated. In summary, as a catalyst, $\alpha-\mathrm{MnO}_{2}-\mathrm{NH}_{2}-\mathrm{GO}$ can not only improve the degradation effect of organic, but also accelerate the reaction rate.

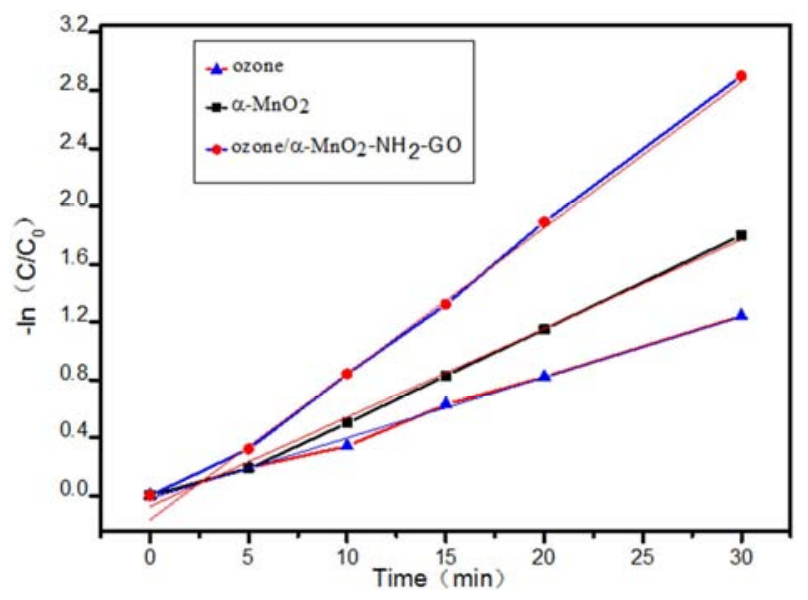

Figure 10. Fitting curve of phenol degradation kinetics.

\section{Conclusion}

In this work, different crystal of $\mathrm{MnO}_{2}$ were prepared by hydrothermal synthesis. The results of oxidation experiments showed that $\alpha-\mathrm{MnO}_{2}$ had the best catalytic performance, the lowest average oxidation state, and the highest relative oxygen content on the surface. The degradation rate reached $95.8 \%$ after 30 minutes with the initial concentration of $50 \mathrm{mg} / \mathrm{L}$ phenol solution reaction, which was mainly caused by the difference in the oxygen vacancy content on the surface of the catalyst. The catalyst was modified by amination and doped $\mathrm{GO}$, and the indicators of the modified catalyst were improved to varying degrees although the oxygen vacancy content on the surface of the catalyst decreased slightly, the performance of the catalyst for ozonation was greatly improved. The degradation rate of the initial concentration of $50 \mathrm{mg} / \mathrm{L}$ phenol solution after 30 minutes reached $99.99 \%$, indicating that the multiphase flow reaction was comprehensively influenced by various factors. Various characterization results indicate that the oxygen vacancy content has an important influence on the catalytic performance, and the catalytic performance improves with the increase of the surface oxygen vacancy content. The catalytic system is proved to be a superoxy radical oxidation system by adding typical free radical scavengers such as tert-butanol, bicarbonate, p-benzoquinone. The reaction kinetics proves that pure ozone oxidation and $\alpha-\mathrm{MnO}_{2}$, the degradation of phenol catalyzed by $\alpha-\mathrm{MnO}_{2}-\mathrm{NH}_{2}-\mathrm{GO}$ are all first-order reaction, but the reaction rate constant of the $\alpha-\mathrm{MnO}_{2}-\mathrm{NH}_{2}$ - $\mathrm{GO}$ catalytic system is 2.4 times that of pure ozone and 1.6 times that of the $\alpha-\mathrm{MnO}_{2}$ oxidation system, which demonstrate doping helps to improve electron transport efficiency, and high oxygen vacancy content helps electron transfer, thereby effectively promoting the improvement of catalytic effect.

\section{Author Contributions}

Gui feng Chen and Wen bo Li are Corresponding authors. Li quan Xia is the first author.

\section{Acknowledgements}

This project was supported by National Key R \& D Program of China (2019YFE0103300), Tiandi Science and Technology Co., LTD. Science and Technology Innovation Venture Capital International Cooperation Project "Research on Coal Chemical Industry High salt Wastewater Catalytic Ozonation Technology Cooperation" (2019-TD-GH002).

\section{References}

[1] J. Jing, W. Li, A. Boyd, et al. (2012) Photocatalytic degradation of quinoline in aqueous $\mathrm{TiO}_{2}$ suspension, $\mathrm{J}$. Hazard. Mater., 237: 247-255.

[2] C. Wang, K. Ma, T. Wu, et al. (2016) Electrochemical mineralization pathway of quinoline by boron-doped diamond anodes, Chemosphere, 149: 219-223.

[3] L. Chang, Y. Zhang, G. Lu, et al. (2014) Internal loop photobiodegradation reactor used for accelerated quinoline degradation and mineralization, Biodegradation, 25: 587-594.

[4] N. Yan, L. Chang, L. Gan, et al. (2013) UV photolysis for accelerated quinoline biodegradation and mineralization, Appl. Microbiol. Biot., 97: 10555-10561.

[5] Z. Bai, Q. Yang, J. Wang, (2016) Catalytic ozonation of sulfamethazine using $\mathrm{Ce}_{0.1} \mathrm{Fe}_{0.9} \mathrm{OOH}$ as catalyst: Mineralization and catalytic mechanisms, Chem. Eng. J., 300: 169-176. 
[6] J. Ma, C. Wang, H. He, (2017) Transition metal doped cryptomelane-type manganeseoxide catalysts for ozone decomposition, Appl. Catal., B, 201: 503-510.

[7] L. Yuan, J. Shen, P. Yan, et al.(2018) Interface mechanisms of catalytic ozonation with amorphous iron silicate for removal of 4-chloronitrobenzene in aqueous solution, Environ. Sci. Technol. J., 52: 1429-1434.

[8] Y. Ren, J. Li, J. Peng, et al. (2018) Strengthening the catalytic activity for ozonation of $\mathrm{Cu} / \mathrm{Al}_{2} \mathrm{O}_{3}$ by an electroless platingcalcination process, Ind. Eng. Chem. Res. J., 57: 1815-1825.

[9] Tang, Z. Pan, L. Li, (2017) pH-insusceptible cobalt-manganese immobilizing mesoporous siliceous MCM-41 catalyst for ozonation of dimethyl phthalate, J. Colloid Inter. Sci., 508: 196-202.

[10] J. Peng, L. Lai, X. Jiang, et al. (2018) Catalytic ozonation of succinic acid inaqueous solution using the catalyst of $\mathrm{Ni} / \mathrm{Al}_{2} \mathrm{O}_{3}$ prepared by electroless plating -calcination method, Sep. Purif. Technol. J., 195: 138-148.

[11] C. Fang, (2019) Facile synthesis of alkaline-earth metal manganites for the efficientdegradation of phenolic compounds via catalytic ozonation andevaluation of the reaction mechanism, J. Colloid Inter. Sci., 551: 164-176.

[12] G. Zhu. (2017) Surface oxygen vacancy induced $\alpha-\mathrm{MnO}_{2}$ nanofiber for highly efficient ozone elimination. Appl. Catal., B, 209: 729-737.

[13] Yang R, Ren C, Teng X, et al. (2017) Study of the Surface Oxygen Vacancies Evolvement on the Single and Bi-Components Manganese Oxide Precursors and their Catalytic Performance. Catal Lett, 147: 727-737.

[14] Lin X, Li S, He H, et al. (2018) Evolution of oxygen vacancies in $\mathrm{MnOx}-\mathrm{CeO}_{2}$ mixed oxides for soot oxidation. Appl. Catal., B, 223: 91-102.

[15] Yang X, Yu X, Lin M, (2019) Enhancement effect of acid treatment on $\mathrm{Mn}_{2} \mathrm{O}_{3}$ catalyst for toluene oxidation. Catal Today, 327: 254-61.

[16] Yajie Yang, Jingbo Jia, Yang Liu, etal. (2018), The effect of tungsten doping on the catalytic activity of $\alpha-\mathrm{MnO}_{2}$ nanomaterial for ozone decomposition under humid condition Applied Catalysis A, General, 562: 132-141.

[17] Xiuqin Tang, Yifeng Wan, Yajing Huang, etal. (2017), Three-dimensional $\mathrm{MnO}_{2}$ porous hollow microspheres for enhancedactivity as ozonation catalysts in degradation of bisphenol A, Journal of Hazardous Materials, 321: 162-172.
[18] Shengpeng Mo, Qi Zhanga, Jiaqi Lia, et al. (2020), Highly efficient mesoporous $\mathrm{MnO}_{2}$ catalysts for the total toluene oxidation: Oxygen-Vacancy defect engineering and involved intermediates using in situ DRIFTS. Appl. Catal. B: Environ., 264: 118464

[19] J. Wang, J. Li, P. Zhang, et al. (2018) Understanding the "seesaw effect" of inter-layered $\mathrm{K}^{+}$with different structure in manganese oxides for the enhanced for-maldehyde oxidation, Appl. Catal. B Environ., 224: 863-870.

[20] Huang N, Qu Z, Dong C, et al. (2018) Superior performance of $\alpha$ and $\beta-\mathrm{MnO}_{2}$ for thetoluene oxidation: Active interface and oxygen vacancy. Appl Catal A Gen, 560: 195-205.

[21] Kai He, Guiqiu Chen, Guangming Zeng, et al. (2018), Three-dimensional graphene supported catalysts for organic dyes degradation, Applied Catalysis B: Environmental, 228: 19-28.

[22] Chao Song, Bei-Bei Guo, Xue-Fei Sun, etal. (2019) Enrichment and degradation of tetracycline using three-dimensional graphene $/ \mathrm{MnO}_{2}$ composites, Chemical Engineering Journal, 358: 1139-1146.

[23] P. Ciambelli, S. Cimino, S. D. Rossi, et al. (2001) AFeO $(\mathrm{A}=\mathrm{La}, \mathrm{Nd}, \mathrm{Sm})$ and $\mathrm{LaFexMgxO}$ perovskites as methane combustion and $\mathrm{CO}$ oxidation catalysts: structural, redox and catalytic properties, Appl. Catal., B, 29: 239-250.

[24] B. P. Barbero, J. A. Gamboa, L. E. Cadús. (2006) Synthesis and characterisation of $\mathrm{La}_{1} \mathrm{AxCaxFeO}$ perovskite-type oxide catalysts for total oxidation of volatile organic compounds, Appl. Catal., B, 65: 21-30.

[25] Hou J, Li Y, Liu L, (2013) Effect of giant oxygen vacancy defects on the catalytic oxidation of OMS-2 nanorods. J Mater Chem A, 1: 6736-41.

[26] Wang F, Dai H, Deng J. (2012) Manganese oxides with rod-, wire-, tube-, and flower-like morphologies: highly effective catalysts for the removal of toluene. Environ Sci Techno., 46: 4034-41.

[27] Guangfei Yu, Yuxian Wang, Hongbin Cao, et al. (2020). Reactive Oxygen Species and Catalytic Active Sites in Heterogeneous Catalytic Ozonation for Water Purification. Environ. Sci. Technol., 54: 5931-5946.

[28] Jianlong Wang, Hai Chen, (2019) Catalytic ozonation for water and wastewater treatment: Recent advances and perspective, Science of the Total Environment, 135: 1-17. 